\title{
Patient Flow at Emergency Department - The Safety Net of Health Care System
}

\author{
Farooq A Jan, M.D., Abid Malik, M.D., Anil Manhas, M.D., Abdul Hakim, M.B., Amir Saeed, M.B., \\ G.H. Yatoo, M.D. \\ Department of Hospital Administration, Sher-i-Kashmir Institute of Medical Sciences, Soura, Srinagar, Kashmir.
}

\section{A B S T R A C T}

BACKGROUND: The unique role of the Emergency Department (ED) has prompted some to call it the safety net of the health care system. Unfortunately the increasing problem of crowding has strained this safety net to the breaking point according to some recent reports.

OBJECTIVE: To study the patient flow at Emergency Department of a tertiary care centre.

METHODS: This prospective study was carried over a period of two weeks at SKIMS in the month of December 2011.

RESULTS: Of 175 patients attending on an average within twenty four hours to SKIMS emergency department, $22.3 \%$ of patients were admitted. 50 patients on an average were being treated at ED reception, the space which is meant for maximum of 16 patients. The hospital crowding was primarily regarded as a consequence of inadequate medical resources. Patients were seen more likely to leave without being seen when ED occupancy exceeded $100 \%$ of the total capacity. The shifting of admitted patients from ED depended on throughput factors in the parent speciality. It was also observed that patients who historically would be admitted through OPD would also find entry through ED.

CONCLUSION: ED crowding is a local manifestation of a systemic disease. The focus has to be multipronged i.e., on Input, Throughput and Output Factors. While as control on input demands wider participation at multicentric community levels, hospitals can focus on the other two class of factors. There has to be clear focus on efficient use of inpatient resources. JMS 2012;15(2):132-35

Key words: Emergency, patient flow, crowding, throughput

During the International crisis the emergency department(ED) crowding has received considerable attention. ${ }^{1}$ The unique role of the ED has prompted some to call it the safety net of the health care system. ${ }^{2}$ Unfortunately the increasing problem of crowding has strained this safety net to the breaking point according to the recent report of the

\section{Correspondence:}

Dr. Farooq Ahmad Jan

Associate Professor

Department of Hospital Administration, Sher-i-Kashmir Institute of Medical Sciences, Soura, Srinagar, Kashmir.

E-mail: janfaro@gmail.com
Institute of Medicine. ${ }^{1}$ Crowding occurs when the identified need for emergency services exceeds available resources for patient care in the emergency department. ${ }^{1}$ ED overcrowding is closely related to a decrease in both subjective patient satisfaction and objective care quality. Attendance peaks have frequently been invoked as one of the major reasons for overcrowding and the "number of arrivals per hour" has been proposed as an explanation for ED performance. However, this indicator does not take into account the effects of patients who remain in ED because of internal reasons. ${ }^{4}$ In this sense, in a preliminary assessment of relative effect of external factors performed in Spain, it has been demonstrated that such internal factors are at least (if not more) as impor- 
tant as external factors in determining ED overcrowding. ${ }^{5}$ Three general themes exist among the causes of ED crowding: Input, Throughput and Output factors. These themes correspond to a conceptual frame work for studying ED crowding. Input factors reflect sources and aspects of patient inflow. Throughput factors reflect bottlenecks within the ED. Output factors reflect bottlenecks in other parts of the health care system that might affect the ED. ${ }^{6}$

Effort was made at Sher-i-Kashmir Institute of Medical Sciences (SKIMS) to study patient flow in ED and identify bottlenecks if any.

\section{Methods}

This prospective study was carried over a period of two weeks at SKIMS in the month of December 2011. The researchers would record at $10 \mathrm{am}$ everyday the number of registrations made at ED during previous twenty four hours. Number of inpatient admissions made through ED during same period would also be recorded. The number of patients being observed at main reception of ED would also be recorded at $10 \mathrm{am}$ everyday. The patients who were at main reception for more than two days would be noted and reasons for their overstay recorded. The patient details for two observation wards one each for Medicine and Surgery were recorded everyday at $10 \mathrm{am}$ in terms of diagnosis, speciality under which admitted and length of stay in ED. The patients who need to stay as inpatient are as a protocol to be shifted to concerned speciality within forty eight hours from ED. The details of patients admitted in different specialities in terms of diagnosis, length of stay and reasons for overstay if any were also noted. Admission and discharge registers in these wards were studied to note down the route of admission i.e., via ED or Out patient Department. To facilitate shifting of patients from ED administration as a policy blocks routine (out Patient) admission of specialities who have long stay patients in ED. The specialities whose out patient admission was blocked were recorded for the study period.

\section{Results}

On an average 175 registrations are made at SKIMS Emergency Department during twenty four hours out of which 39 on an average are admitted with an admission rate of $22.3 \%$. Most of these patients do not earn treatment at a tertiary care facility. On an average 41 patients are under treatment at a given moment at reception of ED as full stay patients. In addition to this 12 patients on an average are being observed at any moment as card patient at the reception. On an average there are six patients at ED reception who have length greater than two days. $60 \%$ of these patients do not have a bed with oxygen facility available in medical observation unit while as $20 \%$ do not have availability of bed in surgical observation unit. Occasionally a stable patient has to be at reception of ED waiting for surgery due to busy emergency OT. There is adequate deployment of medical personnel in ED although the number of nurses deployed needs to be increased. Patients admitted at ED reception are shifted to medical and surgical observation units or directly to the concerned speciality. The average length of stay (ALOS) of patients from different specialities in medical observation unit is shown in Table 1.

TABLE I. Showing ALOS in medical observation unit along with their occupancy

\begin{tabular}{lcc} 
Speciality & ALOS in days & Occupancy in \% age \\
General Medicine & 3.07 & 67 \\
Neurology & 2.3 & 10 \\
Medical Oncology & 2.8 & 9.7 \\
Gastroenterology & 3 & 5.8 \\
Nephrology & 1.2 & - \\
Cardiology & 1.08 & - \\
Clinical Haematology & 0.58 & - \\
\hline
\end{tabular}

The average length of stay of different specialities in medical observation unit is 2 where as average vacant beds is $1.87 \%$ (0.6 beds).

The ALOS of different specialities in surgical observation unit along with their occupancy is shown in Table 2.

TABLE 2. Showing ALOS in surgical observation unit along with their occupancy Speciality ALOS in days Occupancy in \% age

$\begin{array}{lcc}\text { Neurosurgery Unit 1 } & 3.5 & 26.3 \\ \text { Neurosurgery Unit 2 } & 3 & 19.4 \\ \text { General Surgery } & 2.09 & 15.6 \\ \text { Plastic surgery } & 2.8 & 7.14 \\ \text { CVTS } & 2.33 & 4.24 \\ \text { Surgical GE } & 2.31 & - \\ \text { Paediatric Surgery } & 1.3 & - \\ \text { Urology } & 1 & - \\ \text { Surgical Oncology } & 0.17 & -\end{array}$

The ALOS of different specialities in surgical observation unit is 2.05 while as average number of vacant beds daily is $16.07 \%$ ( 4.5 beds).

On an average 1.33 patients/day abscond from ED reception. $95 \%$ of these patients abscond along with patient record because of overcrowding at ED reception, rest of the patients leave because of family problems, go to a private practitioner etc. On an average 9 patients were operated everyday in emergency OT during study period. Patients from observation units are shifted to concerned specialities or are discharged. Some patients need to be shifted to high dependency area.

Patients in specialities are admitted either from ED or from out patient department. Table 3 shows the number of patients admitted from ED and Outpatient Department along with ALOS and number of vacant beds in different specialities. Table 4 shows the specialities whose OPD admission is routinely blocked. 
TABLE 3. Showing average number of patients admitted via ED and Out patient Department(OPD) along with ALOS and average vacant beds in different specialities

\begin{tabular}{lccccc} 
Speciality & $\begin{array}{c}\text { Average number of } \\
\text { patients admitted via OPD }\end{array}$ & $\begin{array}{c}\text { Average number of } \\
\text { patients admitted via ED }\end{array}$ & $\begin{array}{c}\text { ALOS } \\
\text { Average number of } \\
\text { vacant beds }\end{array}$ & $\begin{array}{l}\text { Reasons for long stay if any } \\
\text { Gastroenterology }\end{array}$ \\
General Medicine & 2.82 & 3.94 & 2.94 & 2.87 & - \\
Neurosurgery & 1.2 & 2.94 & 5.9 & 2.18 & - \\
CVTS & 2.35 & 2.35 & 8.59 & 4.93 & Long pre operative waiting time \\
General Surgery & 2.17 & 0.3 & 10.6 & 2.25 & Long pre operative waiting time \\
Plastic surgery & 3.17 & 0.94 & 9.41 & 3.5 & Long pre operative waiting time \\
Neurology & 2.05 & 1 & 12.42 & nil & Preparation for wound for surgery \\
\hline
\end{tabular}

\begin{tabular}{|c|c|c|c|}
\hline Speciality & $\begin{array}{c}\% \text { age of times } \\
\text { Admission is blocked }\end{array}$ & $\begin{array}{l}\text { Speciality } \\
\text { Admission is blocked }\end{array}$ & $\begin{array}{c}\% \text { age of times } \\
\text { blocked }\end{array}$ \\
\hline Neurosurgery & $56,31^{*}$ & Plastic Surgery & 18 \\
\hline General Medicine & 56 & CVTS & 12 \\
\hline Surgical GE & 31 & Gastroenterology & 12 \\
\hline General Surgery & 18 & Neurology & 6 \\
\hline
\end{tabular}

*Separate \%age of two units of the department

\section{Discussion}

175 patients on an average attend SKIMS ED within twenty four hours out of which $22.3 \%$ of patients are admitted. Seeing the profile of patients admitted most of the patients should have been treated at primary care level or secondary care level only. This strongly emphasizes the need to study ED crowding in context of multicenter community networks rather than single institution. ${ }^{7}$ Issue of ambulance diversion (referring patients to other hospitals) may be considered a cause, effect or solution of ED crowding. ${ }^{7}$ SKIMS being a tertiary care centre, it is a important cause of overcrowding. Non urgent visits so called frequent flyer patient have also been seen as a cause of overcrowding. Three studies have identified low acuity ED patients seeking non urgent care in ED and the reason for this being insufficient or untimely access to primary care. ${ }^{8-10}$ Frequent flyers are not a cause of overcrowding at SKIMS. One study reported frequent visitors defined by four or more annual visits contributing to $14 \%$ of total ED visits. ${ }^{11}$ Similar report found that 500 most frequent users of one ED accounted for $8 \%$ of total visits and $29 \%$ of these visits might have been appropriate for Primary care. ${ }^{12}$

As is clear from results 50 patients on an average are being treated at ED reception, the space which is meant for maximum of 16 patients. The hospital crowding is primarily regarded as a consequence of inadequate medical resources. The situation can be potentially improved by optimizing the utilization of medical resources e.g., bed, equipment and personnel. Recent research has shown that highly stochastic process of incoming patients causes the violation of resources which lead to crowding. ${ }^{13}$ However, simply expanding medical care capacity may do little to relieve the emergency department crisis though one hospital increased both space and staffing through an ED reorganization which resulted in the improvement of several crowding outcomes. ${ }^{14}$ Increasing space at SKIMS ED reception which holds more patients than its capacity may give some relief but it will be short lasting if proper referral system is not developed in the state of Jammu \& Kashmir. Inadequate staffing has been identified by some studies to be an important cause of overcrowding. ${ }^{7,15}$ Main reason for patient developement at SKIMS ED is overcrowding. Many articles have characterized patient elopement from ED. Patients have been seen more likely to leave without being seen when ED occupancy exceeded $100 \%$ of the total capacity. ${ }^{16}$ The rate of patients leaving one ED without being seen correlated well with a crowding regression model. ${ }^{17}$ Studies have reported rate of patients leaving without being seen closely correlating with waiting times. ${ }^{17,18}$

The division of ED into Medical and surgical observation units is not justified as it leads to compartmentalisation and creation of dead space. ED over a period of time has evolved as a separate speciality in itself and emergency physicians are trained to handle all sorts of emergencies. In medical observation unit the speciality of General Medicine has an ALOS of 3.07 with an occupancy of $67 \%$, while as in surgical observation unit Neurosurgery has ALOS and percentage occupancy on higher side. The shifting of admitted patients from ED depends on through put factors in the parent speciality. Specialities of Gastroenterology, General Medicine and Neurology have more patients admitted through ED than patients admitted through OPD. Since 2004 EDs in UK have been required to ensure that at least $98 \%$ of patients are either discharged or admitted to hospital within four hours of arrival. Forty four percent of acute trusts are still failing to meet the $98 \%$ target. ${ }^{19}$ Analysis of data from Nationwide Inpatient Sample (NIS), the largest database in U.S in patient care showed number of hospital admissions increased by $15 \%$ in 2006 and admissions from ED increased by $50.4 \%$ in same period. The Proportion of all inpatient stays involving admission from ED increased from 33.5 to $43.8 \%(p<0.001)$. It was observed that patients who historically would be admitted through OPD also would find 
entry through ED. Several explanations were given to this growing role. One frequently cited hypothesis is that reduced access to primary care leads to worsening of patients condition and that emergency physicians are more likely than primary care physicians to admit patients based on the assumption that they are trained to assume the worst and more likely to admit patients with uncertain diagnosis and with whom they don't have an ongoing relationship. ${ }^{20}$ Alternately the trend could be driven by changes in the organization of medical services that favour the rapid diagnostic technologies and early treatment available in the ED. In addition primary care providers and out patient providers are difficult to be contacted by a patient for a sick visit because schedules are full and after hours service is unavailable. Yet since hospital practices have largely been reactive, it is unclear whether this trend reflects high value use of limited emergency care resources and whether it has resulted in more or less appropriate use of scarce inpatient beds. ${ }^{20}$

In conclusion, the increasing use of EDs for inpatient admissions has important implications for the redesign of the healthcare delivery system. The review of literature shows that ED crowding is a local manifestation of a systemic disease. The focus has to be multipronged i.e., on Input, Throughput and Output Factors. While as control on input demands wider participation at multicentric community levels, hospitals can focus on the other two class of factors. There has to be clear focus on efficient use of inpatient resources. More research is required to develop new models of acute care delivery to protect the fragile safety net of health care system.

\section{References}

1. Committee on the future of Emergency Care in the United States Health System. Hospital Based Emergency Care: At the Breaking point. Washington DC; National Academics Press: 2006.

2. Asplin BR. Trying a knot in the unravelling health care safety net. Acad Emerg Med 2001; 8:1075-1079.

3. American College of Emergency Physicians. Crowding. Ann Emerg Med 2006; 47:585.

4. Yamamoto LG, Iwamoto LM, Yamamoto KS, et al. Effects of environmental conditions on emergency department use by wheezing children. Ann Emerg Med 1993;22:523-9.

5. Miro O, Sanchez M, Call- Vinent B, et al. Estimacion del efecto relative que ejercon los determinants externas e internas sobre la eficacia deun service de urgencias de medicina. Med Clin (Barc) 2000;115:294-6.

6. Asplin Br, Magid DJ, Rhodes KV, et al. A conceptual model of emergency department crowding. Ann Emergency Med 2003;42:173-180.
7. Nathan HR, Dominik A. Systematic Review of Emergency Department Crowding: Causes, Effects and solutions. Annals of Emergency Medicine 2008;52: 126-136.

8. Grumbach K, Keane D, Bindman A. Primary care and Public emergency department crowding. Am J Public Health 1993; 83: 372-378.

9. Afilalo J, Marinovich A, Afilalo M, et al. Nonurgent Emergency department patient characteristics and barriers to primary care. Acad Emerg Med 2004;11:13021310.

10. Howard MS, Davis BA, Anderson C, et al. Patients perspective on choosing the emergency Department for non urgent Medical care: a qualitative study exploring one reason for overcrowding. J Emerg Nurs 2005;31:429-435.

11. Huang JA, Tsai WC, Chen YC, et al. Factors associated with frequent use of emergency services in a medical centre.J Formas Med Asso 2003;102:222-228.

12. Dent AW, Phillips GA, Chenhall AJ, et al. The heaviest repeat users of an inner City Emergency are not general practice patients. Emerg Med 2003;15:322-329.

13. Lei Zhao, Bernt Lie. Modelling and simulation of patient flow in hospitals for resource utilization. Telemark University College N-3901. Norway.

14. Miro O, Sanchez M, Espinosa G, et al. Analysis of patient flow in the Emergency Department and the effect of an extensive reorganization. Emerg Med J 2003; 20:143-148.

15. Lambe S, Washington DL, Fink A, et al. Waiting times in California's Emergency Departments. Ann Emerg Med 2003;41:35-44.

16. Palevoi SK, Quinn JV, Kramer NR. Factors associated with patients who leave without being seen. Acad Emerg Med 2005;12:232-236.

17. Weiss SJ, Ernet AA, Derlet R, et al. Relationship between National ED over crowding scale and the number of patients who leave without being seen in an academic ED. Am J Emerg Med 2005; 23:288-294.

18. Rowe BH, Channan P, Bullard M, et al. Characteristics of Patients who leave Emergency Departments without being seen. Acad Emerg Med 2006;13: 848-852.

19. Julie Eatock, Malcolm Clarke. Meeting the four hour dead line in an A \& E department. Journal of Health Organization and Management 2011;25:606-624.

20. Jeremiah D Schuur, Arjun K Venkatesh. The Growing Role of Emergency Departments in Hospital Admissions. NEngJ Med 2012;367:391-393. 